\title{
Simvastatin induces apoptosis in PTEN-haploinsufficient lipoma cells
}

\author{
FRANZISKA KÄSSNER ${ }^{1}$, TINA SAUER ${ }^{1}$, MELANIE PENKE ${ }^{1}$, SANDY RICHTER $^{1}$, KATHRIN LANDGRAF $^{1,2}$, \\ ANTJE KÖRNER $^{1,2}$, WIELAND KIESS ${ }^{1}$, NORMAN HÄNDEL ${ }^{1}$ and ANTJE GARTEN ${ }^{1,3}$ \\ ${ }^{1}$ University Hospital for Children and Adolescents, Center for Pediatric Research Leipzig (CPL); \\ ${ }^{2}$ Leipzig University Medical Center, IFB Adiposity Diseases, D-04103 Leipzig, Germany; \\ ${ }^{3}$ University of Birmingham, Institute of Metabolism and Systems Research (IMSR), Birmingham B15 2TT, UK
}

Received June 9, 2017; Accepted January 31, 2018

DOI: $10.3892 /$ ijmm.2018.3568

\begin{abstract}
Adipose tissue tumors (lipomas) frequently develop in patients with heterozygous germ line phosphatase and tensin homolog (PTEN) mutations. simvastatin has been demonstrated to exhibit antitumor effects, and so the aim of the present study was to assess the effects of simvastatin on the growth of human PTEN haploinsufficient lipoma cells. Whether the effects of simvastatin in lipomas are mediated via PTEN upregulation was also assessed. The results of the present study revealed that simvastatin treatment reduced cell viability and induced apoptosis in human lipoma cells. Furthermore, it was demonstrated that the expression of cellular PTEN mRNA and protein was increased following simvastatin stimulation. In addition, the phosphorylation of protein kinase B and downstream targets of mammalian target of rapamycin and 4E-binding protein (4E-BP)-1 was attenuated. It was also demonstrated that simvastatin induced PTEN transcriptional upregulation by increasing peroxisome proliferator-activated receptor (PPAR) $\gamma$ expression. The small interfering RNA-mediated knockdown of PPAR $\gamma$ abrogated the stimulatory effect of simvastatin on the PTEN protein, but did not influence apoptosis. The results of the present study
\end{abstract}

Correspondence to: Dr Antje Garten, University of Birmingham, Institute of Metabolism and Systems Research, Wolfson Drive, Birmingham B15 2TT, UK

E-mail: a.garten@bham.ac.uk

Abbreviations: 4E-BP-1, 4E-binding protein; mTOR, mammalian target of rapamycin; PTEN, phosphatase and tensin homologue; PHTS, PTEN hamartoma tumor syndrome; PI3K, phosphatidylinositol 3-kinase; PPAR $\gamma$, peroxisome proliferator-activated receptor gamma; siRNA, small interfering RNA

Key words: human adipocytes, phosphatase and tensin homologue, protein kinase B, simvastatin, peroxisome proliferator-activated receptor $\gamma$, phosphatase and tensin homologue hamartoma tumor syndrome, lipomatous overgrowth suggest that simvastatin may be beneficial for patients with inoperable PTEN haploinsufficient lipomas.

\section{Introduction}

Benign tumors of adipose tissue are often exhibited in humans with rare phosphatase and tensin homolog (PTEN) Hamartoma Tumor Syndrome (PHTS), which is caused by heterozygous germ line mutations within the tumor suppressor PTEN gene (1). Although noncancerous, these lipomas frequently develop to form extended fatty tissue tumors (lipomatosis), which may infiltrate other tissues and cause numerous side effects, including organ obstruction, resulting in loss of function and chronic pain (2). A previous study assessed a child with a severe PHTS phenotype who exhibited abdominal lipomatosis (3). It was demonstrated that an individual treatment attempt using the mammalian target of rapamycin complex (mTOR)1 inhibitor sirolimus led to an improvement in the patient's general condition and a decrease in thymus size; however, lipomatosis regression was not observed (3). At present, no targeted therapies for the treatment of PHTS-associated lipomatosis exist. Surgical excision of the tumor and symptomatic treatment remain the only form of therapy available (4). There is therefore an urgent need to uncover novel therapeutic approaches for patients with PHTS and non-resectable adipose tissue tumors.

Statins, also known as 3-hydroxy-3-methylglutaryl-CoA reductase inhibitors, are widely utilized to decrease serum cholesterol levels (5). Previous studies have demonstrated that statins elicit numerous non-lipid modifying effects, which have been revealed to exhibit anti-tumor effects in vitro, in vivo and in epidemiological studies (6-9). In particular, simvastatin was demonstrated to increase PTEN protein levels and activity, thus downregulating the activation of the phosphatidylinositol 3-kinase (PI3K)/protein kinase B (AKT) signaling pathway (10-13). Furthermore, a case report of a 54-year-old man described a dramatic reduction of an isolated subcutaneous lipoma associated with simvastatin therapy (14).

The aim of the present study was to assess the effects of simvastatin on three lipoma cell lines, termed lipoma PTEN-deficient 1-3 (LipPD1-3), established from the resected lipoma tissue of pediatric patients with heterozygous germ line 
PTEN deletion or mutations. It was hypothesized that simvastatin treatment may lead to attenuated cell growth or the induction of apoptosis in these PTEN haploinsufficient lipoma cells by increasing levels of the PTEN protein.

\section{Materials and methods}

Informed consent. Written informed consent was provided by the parents of all patients enrolled in the present study. A total of 3 patients ( 2 male, 1 female) and 2 healthy control patients ( 1 male, 1 female), aged 0-18 years were enrolled in the present study. All patients were admitted to the Hospital for Child and Adolescent Medicine (Leipzig University, Leipzig, Germany) and samples were collected between July 2007 and December 2016. Patients with morbidities other than PHTS were excluded. One patients received sirolimus following lipoma resection (3). All LipPD cells used in this study were obtained from lipomatous adipose tissue that was resected for diagnostic and therapeutic reasons. Control primary pre-adipocytes were removed from adipose tissue obtained from pediatric or young adult patients during routine surgery. Ethical approval for these studies was obtained from the Ethics Committee of the University of Leipzig (ref. no. 425-12-171220; Leipzig, Germany).

Cell lines, cell culture and treatments. Genetic analyses of PTEN revealed a heterozygous deletion affecting exons 2-9 of 9 of PTEN in LipPD1 cells $(3,15)$. A heterozygous PTEN mutation was detected in LipPD2 (c.404T $>$ A, p.I135K) and LipPD3 (exon 1, c.76A>C, p.T26P). A schematic presentation of the genetic changes in PTEN is presented in Fig. 1A. The following cells were used as PTEN wild-type controls: Simpson-Golabi-Behmel (SGBS, kindly supplied by Dr M. Wabitsch, University Hospital, Ulm, Germany) $(16,17)$ cells and normal primary pre-adipocytes obtained from pediatric or healthy young adult adipose tissue. All cell strains were established according to protocols as described previously $(3,17)$. Cells were maintained in Dulbecco's Modified Eagle's medium (DMEM)/F12 medium supplemented with $10 \%$ fetal calf serum, glutamine $(2 \mathrm{mM})$, biotin $(33 \mathrm{mM})$ and pantothenic acid (17 mM; all from Biochrom, Ltd., Cambridge, $\mathrm{UK})$ at $37^{\circ} \mathrm{C}$ in a humidified atmosphere containing $5 \% \mathrm{CO}_{2}$. InSolution $^{\mathrm{TM}}$ simvastatin sodium salt was purchased from EMD Millipore (Billerica, MA, USA). Medium was replaced with serum-free DMEM $24 \mathrm{~h}$ prior to cell stimulation with 0 , $0.1,1$ and $10 \mu \mathrm{M}$ simvastatin for $6,12,24$ or $48 \mathrm{~h}$.

Cell viability and apoptosis. The effect of simvastatin on proliferation was measured using a Cell Proliferation Reagent WST-1 (Roche Diagnostics GmbH, Mannheim, Germany) according to the manufacturer's protocol. Cells were seeded in 96-well plates at a density of 10,000 cells $/ \mathrm{cm}^{2}$ and incubated for $48 \mathrm{~h}$ with $0,0.1,1$ and $10 \mu \mathrm{M}$ simvastatin. Apoptosis was determined using Annexin V-fluorescein isothiocyanate (FITC; BD Pharmingen; BD Bioscience, San Jose, CA, USA)/propidium iodide (PI) staining according to manufacturer's protocol. Briefly, cells were seeded at a density of 5,000 cells $/ \mathrm{cm}^{2}$ and incubated for $48 \mathrm{~h}$ with 0,1 or $10 \mu \mathrm{M}$ simvastatin. Cells were trypsinized and incubated with Annexin V-FITC/PI for $10 \mathrm{~min}$ at $4^{\circ} \mathrm{C}$ in the dark. Annexin V-FITC-positive cells represent early apoptosis and Annexin V-FITC/PI double positive cells indicate late apoptotic cells.

Reverse transcription quantitative polymerase chain reaction $(R T-q P C R)$. For qPCR analysis mRNA was extracted from LipPD1 cells using the RNeasy mini kit (Qiagen $\mathrm{GmbH}$, Hilden, Germany) according to the manufacturer's protocol. A total of $1 \mu \mathrm{g}$ mRNA was reverse transcribed at $39^{\circ} \mathrm{C}$ for $1 \mathrm{~h}$ into cDNA using M-MLV Reverse Transcriptase (Invitrogen; Thermo Fisher Scientific, Inc., Waltham, MA, USA). PCR reactions were performed using Taqman Mastermix FAST qPCR Master Mix Plus Low ROX (Eurogentec, Liege, Belgium) or Absolute qPCR SYBR-Green Low ROX Mix (Thermo Fisher Scientific, Inc.) and the Applied Biosystems 7500 Real-Time PCR System (Applied Biosystems; Thermo Fisher Scientific, Inc.). Primers and probes were designed using the PrimerExpress software version 3.0 (Applied Biosystems; Thermo Fisher Scientific, Inc.) and sequences are presented in Table I. The following thermocycling conditions were used: Activation at $95^{\circ} \mathrm{C}$ for $15 \mathrm{~min}, 40$ cycles of denaturation at $95^{\circ} \mathrm{C}$ for $15 \mathrm{sec}$, annealing at $60^{\circ} \mathrm{C}$ for $30 \mathrm{sec}$, elongation at $72^{\circ} \mathrm{C}$ for $30 \mathrm{sec}$. A standard curve of serial dilutions of plasmid DNA of the respective target gene was included on each plate. The copy number of each sample was calculated from the standard curve and normalised to the mean of the two housekeeping genes Tata box binding protein $(T B P)$ or hypoxanthine phosphoribosyltransferase (HPRT) expression (18).

Western blot analysis. For protein analysis, cells were lysed with modified radioimmunoprecipitation assay buffer $[50 \mathrm{mM}$ Tris $\mathrm{HCl}$; pH 7.4; $1 \%$ NP-40; $0.25 \%$ sodium deoxycholate; 1x Roche complete proteases inhibitor cocktail (Roche Diagnostics $\mathrm{GmbH}$ ); $1 \mathrm{mM}$ EDTA; $1 \mathrm{mM}$ sodium orthovanadate; and $1 \mathrm{mM}$ sodium fluoride], protein concentrations were determined using a DC protein assay (Bio-Rad Laboratories, Inc., Hercules, CA, USA) and proteins (20 $\mu \mathrm{g} /$ lane) were separated by $10 \%$ SDS-PAGE. Following semi-dry transfer onto nitrocellulose membranes, membranes were blocked using $5 \%$ non-fat dry milk in TBS buffer containing $0.1 \%$ Tween-20 (TBST) for $1 \mathrm{~h}$ at room temperature. Blots were then incubated overnight at $4^{\circ} \mathrm{C}$ with the appropriate primary antibody. The antibodies utilized in western blotting are summarized in Table II. Blots were washed three times for $5 \mathrm{~min}$ with TBST and incubated with horseradish peroxidase (HRP)-goat anti rabbit (P-0448) or HRP-goat anti mouse (P-0447 antibodies (Dako; Agilent Technologies, Inc., Santa Clara, CA, USA) at a dilution of 1:2,000 for $2 \mathrm{~h}$ at room temperature. Protein bands were detected using Luminata Classico Western horseradish peroxidase Substrate (EMD Millipore) or Amersham ECL Prime Western Blotting Detection Reagent (GE Healthcare, Chicago, IL, USA). Glyceraldehyde-3-phosphate dehydrogenase (EMD Millipore) was used as a loading control. ImageJ 1.41 was used for densitometric analysis (National Institutes of Health, Bethesda, MD, USA).

Small interfering (si)RNA-mediated knockdown of PPAR $\gamma$. LipPD1 cells were microporated using the Neon Transfection System $100 \mu \mathrm{l}$ kit (Invitrogen; Thermo Fisher Scientific, Inc.) with the PPAR $\gamma$ ON-TARGETplus SMARTpool siRNA 
Table I. Primer and probe sequences.

\begin{tabular}{lll}
\hline Gene & Direction & \multicolumn{1}{c}{ Sequence } \\
\hline PTEN & $\begin{array}{l}\text { Forward } \\
\text { Reverse }\end{array}$ & GTTTACCGGCTCAAAT \\
PPAR $\gamma$ & Forward & GATCCAGTGGTTGCAGATTACAA \\
& Reverse & GAGGGAGTTGGAAGGCTCTTC \\
& Probe & TGACCTGAAACTTCAAGAGTACCA \\
& & AAGTGCAA \\
TBP & Forward & TTGTAAACTTGACCTAAAGACCAT \\
& & TGC \\
& Reverse & TTCGTGGCTCTCTTATCCTCATG \\
& Probe & AACGCCGAATATAATCCCAAGCGGT \\
HPRT & Forward & GGCAGTATAATCCAAAGATGGTCAA \\
& $\begin{array}{l}\text { Reverse } \\
\text { Probe }\end{array}$ & GTCTGGCTTATATCCAACACTTCGT \\
& CAAGCTTGCTGGTGAAAAGGACCCC
\end{tabular}

PTEN, phosphatase and tensin homolog; PPAR $\gamma$, peroxisome proliferator-activated receptor; TBP, tata box binding protein, HPRT, hypoxanthine phosphoribosyltransferase.

reagent and the respective negative control (ON-TARGETplus control pool; GE Healthcare Dharmacon, Inc., Lafayette, $\mathrm{CO}$, USA) as previously described (18). A total of $10^{6}$ cells were transfected with siRNA at a final concentration of $500 \mathrm{nmol} / 1$, seeded at a density of $10^{5}$ cells/well in 6 well plates and cultured for $24 \mathrm{~h}$. The following day, the culture medium was replaced with serum-free DMEM for $24 \mathrm{~h}$. Cells were then stimulated using simvastatin $(10 \mu \mathrm{M})$ as above.

Statistical analysis. Data are presented as the mean \pm standard error of the mean of at least three independent experiments. Significant differences were determined using GraphPad Prism 6 software (GraphPad Software, Inc., La Jolla, CA, USA) and the unpaired Student's t-test or one-way analysis of variance followed by a post hoc Bonferroni multiple comparison test. $\mathrm{P}<0.05$ was considered to indicate a statistically significant difference.

\section{Results}

Decreased PTEN protein levels and enhanced AKT in PTEN deficient lipoma cells. Basal PTEN mRNA and protein levels were analyzed to assess the impact of the heterozygous PTEN deletions or mutations (Fig. 1A) on lipoma cells. Lipoma cells with a large heterozygous PTEN deletion (3) possessed a significantly lower PTEN mRNA expression compared with PTEN wild-type control pre-adipocytes $(\mathrm{P}<0.05$; Fig. 1B). PTEN mRNA expression was similar in lipoma cells with PTEN point mutations and non-mutant cells (Fig. 1B). However, in all three lipoma cell cultures, PTEN protein levels were lower compared with PTEN wild-type control cells $(\mathrm{P}<0.05$; Fig. $1 \mathrm{C})$. It was then assessed whether reduced PTEN protein levels led to enhanced AKT phosphorylation. Mutation-positive cells exhibited significantly higher levels of phosphorylated AKT (Thr308) compared with control cells (LipPD1 and LipPD3; P<0.05) (Fig. 1D).

Simvastatin treatment induces apoptosis in lipoma cells. The effect of simvastatin on the viability of lipoma cells was determined following incubation for 24, 48 and $72 \mathrm{~h}$ (Fig. 2A). Simvastatin at $10 \mu \mathrm{M}$ significantly decreased the viability of LipPD1, LipPD2 and LipPD3 cells to 67.5 $\pm 8.3,68.0 \pm 14.3$ and $64.0 \pm 9.2 \%$ at $48 \mathrm{~h}$ and to $42.3 \pm 8.8 \%, 43.3 \pm 14.0 \%$ and $37.2 \pm 6.9 \%$ at $72 \mathrm{~h}$ incubation, $(\mathrm{P}<0.05$; Fig. $2 \mathrm{~A}$ and $\mathrm{B})$. At the same dose and incubation time, simvastatin induced apoptosis by $28 \%$ in LipPD1 compared with LipPD1 cells incubated without simvastatin (Fig. 2C). Following incubation with $10 \mu \mathrm{M}$ simvastatin, cells were equally distributed between early and late apoptotic phases. No effect on cell viability was observed following an incubation of $24 \mathrm{~h}$ (data not shown).

Simvastatin treatment decreases AKT/mTOR activation. Previous studies have demonstrated that simvastatin upregulates PTEN transcription (8-10), and so PTEN mRNA expression in lipoma cells was assessed following incubation with simvastatin. Stimulation with $10 \mu \mathrm{M}$ simvastatin resulted in a significant increase in the expression of PTEN mRNA to 1.4 \pm 0.1 -fold in LipPD1 compared with control cells following a $6 \mathrm{~h}$ incubation $(\mathrm{P}<0.05$; data not shown). The effect of simvastatin on the PTEN protein and AKT/mTOR pathway activation following $6,12,24$ and $48 \mathrm{~h}$ of incubation was then assessed. Simvastatin $(10 \mu \mathrm{M})$ resulted in an increase in phosphorylated and total PTEN protein levels in LipPD1 cells when incubated for $24 \mathrm{~h}$ (Fig. 3A-C). In addition, a downregulation in AKT phosphorylation at T308 and S473 (Fig. 3A, D and E) was observed following 24 and $48 \mathrm{~h}$ incubation. The activation of mTOR, a downstream target of AKT, was then examined. The results demonstrated that $48 \mathrm{~h}$ incubation with $10 \mu \mathrm{M}$ simvastatin significantly decreased mTOR1 phosphorylation at Ser 2448 by $48.8 \pm 1.2 \%(\mathrm{P}<0.05$; Fig. $3 \mathrm{~F}$ and $\mathrm{G})$ and phosphorylation of the mTOR target 4E-binding protein-1 (4EBP-1) by $64.9 \pm 1.2 \%(\mathrm{P}<0.05$; Fig. $3 \mathrm{~F}$ and $\mathrm{H})$. Increased PTEN protein levels were also observed in LipPD2 and LipPD3 cells following $6 \mathrm{~h}$ of incubation with $10 \mu \mathrm{M}$ simvastatin (both $\mathrm{P}<0.05$; data not shown). These results indicate that simvastatin incubation affects PTEN protein levels and AKT/mTOR activation in a time-dependent manner.

PPAR $\gamma$ mediates simvastatin action on PTEN protein expression, but not on apoptosis. The present study aimed to identify the mediators of simvastatin. Previous studies have demonstrated that simvastatin acts through the activation of nuclear factor $(\mathrm{NF}) \kappa \mathrm{B}(9,13,19)$. However, in the present study, no significant effect on $\mathrm{NF}-\kappa \mathrm{B}$ phosphorylation was observed following incubation with simvastatin (data not shown). Additionally, no significant upregulation of the NF- $\kappa \mathrm{B}$ target protein B-cell lymphoma-2 $(13,20,21)$ was detected (data not shown). Previous studies have indicated the ability of the transcriptional regulator PPAR $\gamma$ to induce PTEN mRNA (22-25). The results of the present study demonstrated that a $6 \mathrm{~h}$ simvastatin incubation significantly upregulated LipPD1 cell PPAR $\gamma$ protein expression by $1.88 \pm 0.3$-fold $(\mathrm{P}<0.05$; Fig. $4 \mathrm{~A})$. It was then determined whether knockdown of PPAR $\gamma$ abrogated the stimulatory effect of simvastatin on PTEN levels. 
Table II. Primary antibodies utilized in western blotting.

\begin{tabular}{|c|c|c|c|}
\hline Antibody & Supplier & Cat. no. & Dilution \\
\hline 4E-BP1 & NEB & 9644 & $1: 1,000$ \\
\hline Phospho-4E-BP1 (Threonine 37/46) & NEB & 2855 & $1: 1,000$ \\
\hline $\mathrm{AKT}$ & NEB & 9272 & $1: 1,000$ \\
\hline Phospho-AKT (Threonine 308) & NEB & 4056 & $1: 1,000$ \\
\hline Phospho-AKT (Serine 473) & NEB & 4060 & $1: 1,000$ \\
\hline GAPDH & Merck KGaA & MAB374 & $1: 100,000$ \\
\hline p44/42 MAPK (ERK1/2) & NEB & 9102 & $1: 1,000$ \\
\hline Phospho-p44/42 mitogen activated protein & NEB & 9101 & $1: 1,000$ \\
\hline \multicolumn{4}{|l|}{ kinase (ERK1/2) (Threonine 202/Tyrosine 204) } \\
\hline mTOR & NEB & 2983 & $1: 1,000$ \\
\hline Phospho-mTOR (Serine 2448) & NEB & 2971 & $1: 1,000$ \\
\hline Peroxisome proliferator-activated receptor $\gamma$ & NEB & 2443 & $1: 1,000$ \\
\hline Phosphatase and tensin homolog & NEB & 9559 & $1: 1,000$ \\
\hline
\end{tabular}

NEB is located in Ipswich, MA, USA. Merck KGaA is located in Darmstadt, Germany. 4E-BP1, 4E-binding protein-1; phospho, phosphorylated; AKT, protein kinase B; ERK, extracellular signal-related kinase; mTOR, mammalian target of rapamycin.

A
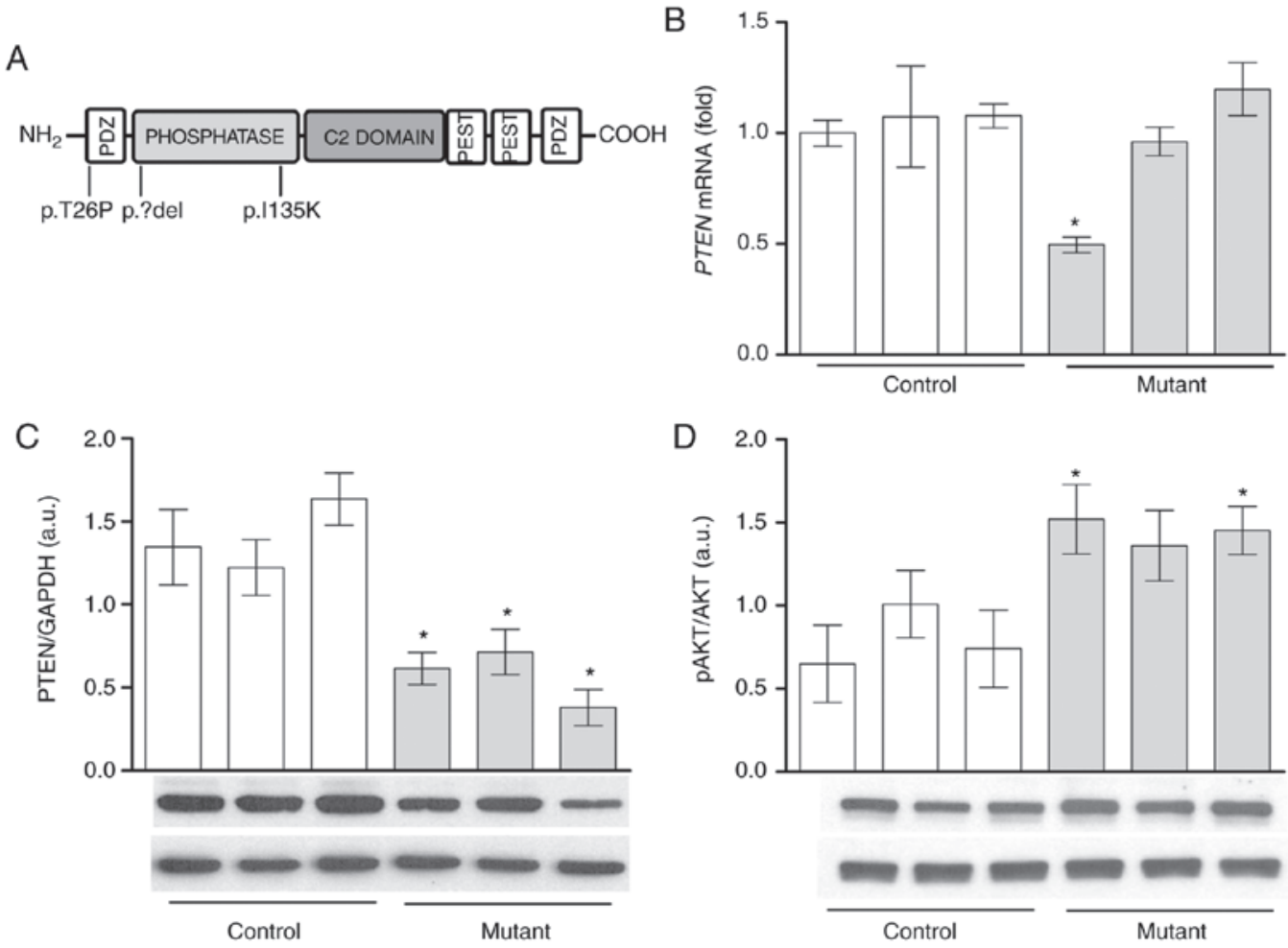

Figure 1. AKT phosphorylation is increased with lower PTEN protein levels in lipoma cells compared with PTEN wild-type pre-adipocytes. (A) Schematic representation of the PTEN protein domains and mutation sites. Heterozygous deletion (LipPD1) or mutations (LipPD2 and LipPD3) of the PTEN gene are depicted. PTEN (B) mRNA and (C) protein expression in mutant lipoma cells (LipPD1-3) in comparison with PTEN wild-type control (SGBS, normal primary) pre-adipocytes. mRNA data were normalized to the Tata box binding protein and Glyceraldehyde-3-phosphate dehydrogenase, respectively. (D) Phosphorylation of AKT (threonine 308) in mutant lipoma cells (LipPD1-3) compared with wild-type control cells. Phosphorylation of AKT was normalized to total AKT levels. All data are presented as the mean \pm standard error of the mean. Statistical analysis was performed using a Student's t-test. *P $<0.05$ vs. the mean of all three PTEN wild-type cells. AKT, protein kinase B; PTEN, phosphatase and tensin homolog; LipPD1-3, lipoma PTEN-deficient 1-3; p, phosphorylated; PDZ, Post synaptic density protein (PSD95), Drosophila disc large tumor suppressor (Dlg1) and zonula occludens-1 protein (ZO-1), PEST, proline (P), glutamic acid (E), serine (S) and threonine (T).

siRNA-mediated knockdown of PPAR $\gamma$ to $34.8 \pm 1.2 \%$ was confirmed at the protein level (Fig. 4B) and this knockdown significantly attenuated the upregulation of PTEN mRNA and protein induced by simvastatin $(\mathrm{P}<0.05$; Fig. 4C). These results indicate that simvastatin induces PTEN expression in a PPAR $\gamma$-dependent manner in LipPD1 cells. Furthermore, 

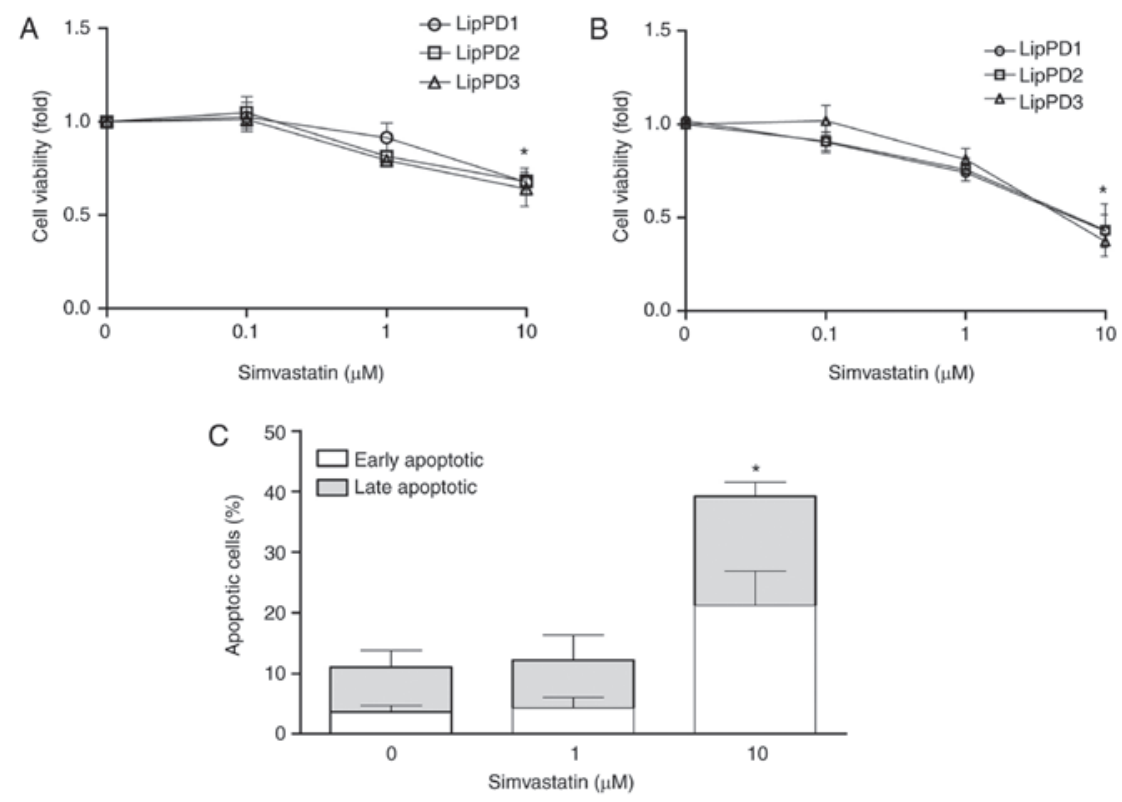

Figure 2. Simvastatin treatment decreased lipoma cell viability and induced apoptosis. LipPD1-3 cells were incubated with increasing doses of simvastatin. Cell viability was measured using a WST-1 assay following (A) 48 and (B) $72 \mathrm{~h}$ incubation. Data were normalized to the untreated control. (C) LipPD1 cells were stained with Annexin V/propidium iodide following $48 \mathrm{~h}$ incubation with simvastatin and apoptosis was assessed. Data are presented as the mean \pm standard error of the mean of three independent experiments. Statistical analysis was performed using one-way analysis of variance and the post-hoc Bonferroni test. ${ }^{*} \mathrm{P}<0.05$ vs. untreated cells. LipPD1-3, lipoma phosphatase and tensin homolog-deficient 1-3.
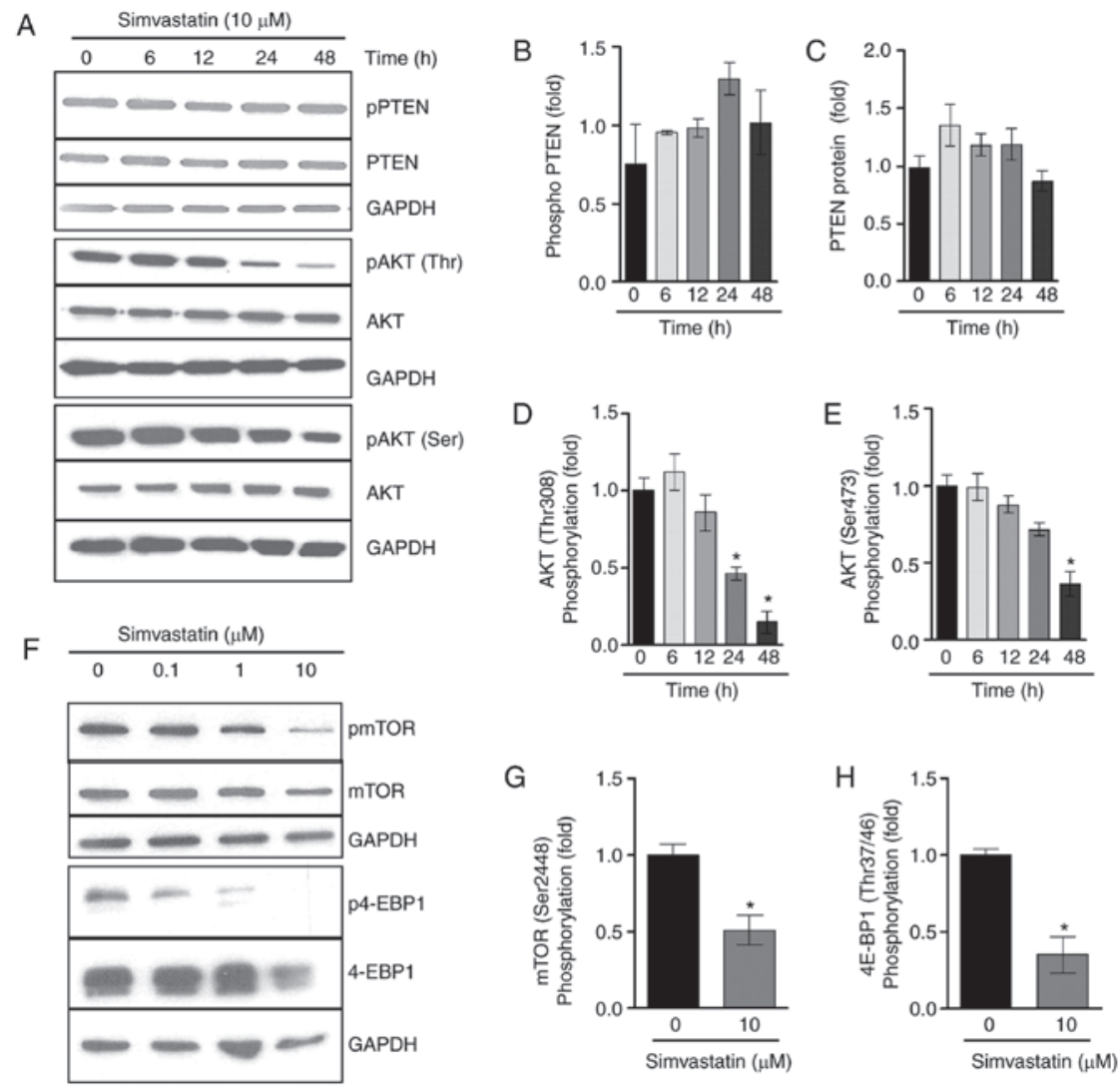

Figure 3. Simvastatin treatment decreased AKT/mTOR activation following prolonged treatment. (A) LipPD1 cells were stimulated with $10 \mu \mathrm{M}$ simvastatin in culture medium for $6,12,24$ or 48 h. PTEN mRNA expression was quantified using reverse transcriptase polymerase chain reactions. Data were normalized to TBP and then compared with the expression level exhibited in the untreated controls. Relative expression of (B) phospho PTEN, (C) PTEN, (D) phospho AKT and (E) total AKT. (F) LipPD1 cells were stimulated with $10 \mu \mathrm{M}$ simvastatin in culture medium for $48 \mathrm{~h}$. Relative expression of (G) mTOR (Ser2448) and (H) 4E-BP1 (Thr37/46) were calculated. All data are presented as the mean \pm standard error of the mean. Statistical analysis was performed using a Student's t-test or one-way analysis of variance with a post hoc Bonferroni test. "P<0.05 vs. untreated cells. AKT, protein kinase B; mTOR, mammalian target of rapamycin; PTEN, phosphatase and tensin homolog; phospho, phosphorylated; LipPD1-3, lipoma PTEN-deficient 1-3; TBP, Tata box binding protein; Ser, Serine; Thr, threonine; GAPDH, glyceraldehyde-3-phosphate dehydrogenase; pAKT, phosphorylated AKT; 4E-BP1, 4E-binding protein-1; pmTOR, phosphorylated mTOR; p4E-BP1, phosphorylated 4E-BP1. 

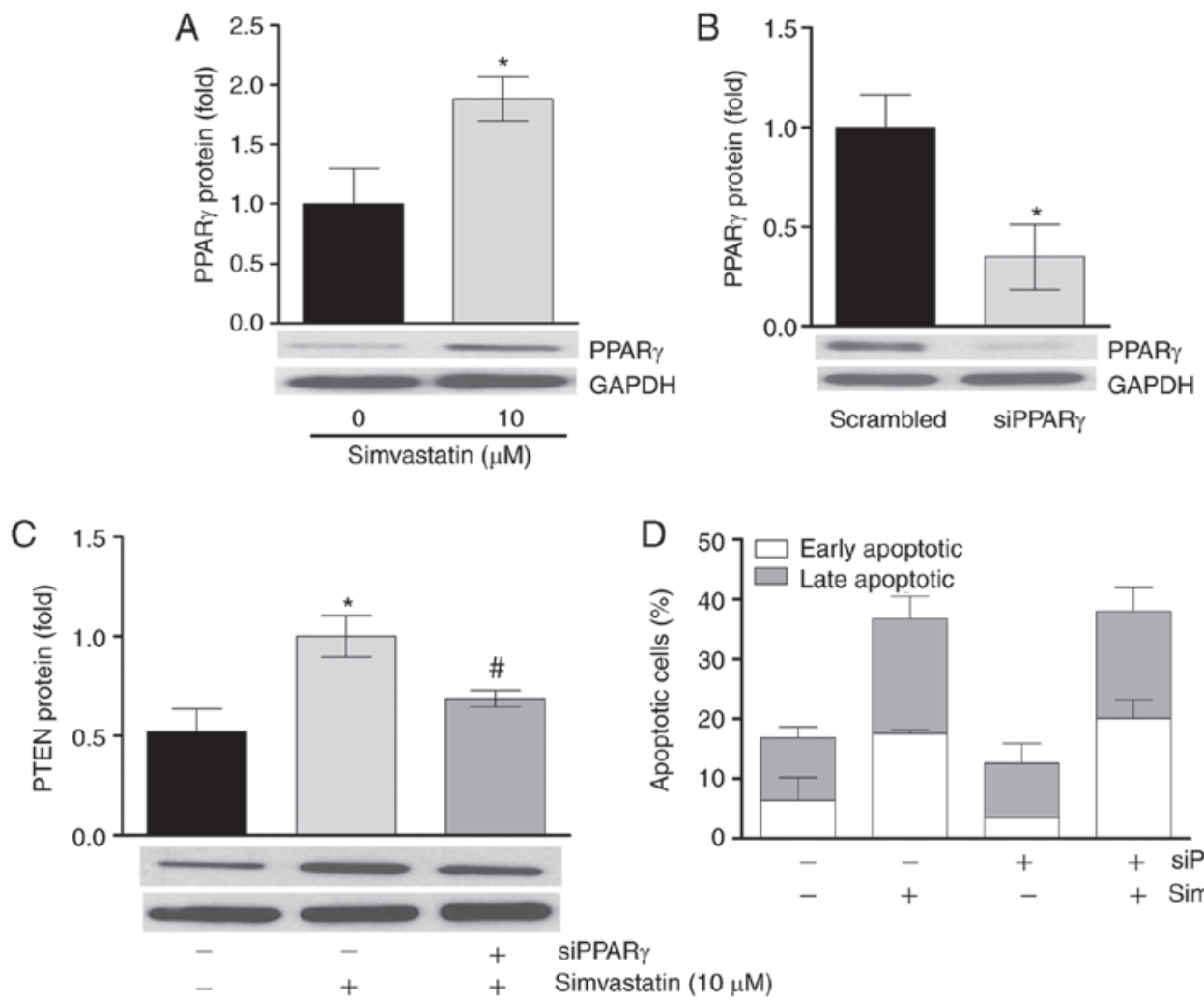

Figure 4. PPAR $\gamma$ knockdown attenuates simvastatin-induced upregulation of the PTEN protein and has no effect on apoptosis. (A) LipPD1 cells were incubated with $10 \mu \mathrm{M}$ simvastatin in culture medium for $6 \mathrm{~h}$. PPAR $\gamma$ protein levels were quantified using western blot analysis and normalized to GAPDH. LipPD1 cells were then transfected with siRNA against PPAR $\gamma\left(\right.$ siPPAR $\left.\gamma^{+}\right)$or non-targeted control siRNA (scrambled). (B) Knockdown of PPAR $\gamma$ was confirmed using western blot analysis. (C) PTEN protein levels of cells transfected with PPAR $\gamma$ siRNA or non-targeted control siRNA following incubation with simvastatin or vehicle were assessed. (D) Induction of apoptosis following transfection with PPAR $\gamma$ siRNA or non-targeted control siRNA. Apoptosis was detected using Annexin V/propidium iodide staining. Data are presented as the mean \pm standard error of the mean. Statistical analysis was performed using Student's t-test. ${ }^{*} \mathrm{P}<0.05$ vs. control cells; ${ }^{*} \mathrm{P}<0.05$ vs. simvastatin-treated cells. PPAR $\gamma$, peroxisome proliferator-activated receptor; PTEN, phosphatase and tensin homolog; LipPD1, lipoma PTEN-deficient 1; GAPDH, glyceraldehyde-3-phosphate dehydrogenase; siRNA, small interfering RNA.

the present study assessed whether PPAR $\gamma$ knockdown would effect simvastatin-induced apoptosis. No significant differences in apoptosis induction or in the distribution of cells between early and late apoptotic phases were identified in PPAR $\gamma$-knockdown cells compared with control-transfected cells following stimulation with simvastatin (Fig. 4D).

\section{Discussion}

At present, treatment options for patients with non-resectable PHTS-associated lipomatosis are limited. Sirolimus, an inhibitor of mTOR1, was successfully used to treat patients with other PHTS-associated complications (23-25). However, it was not effective at reducing lipoma growth in a patient with PHTS due to the heterozygous germ line deletion of PTEN (3). The aim of the present study was to test the effects of simvastatin on the growth of human lipoma cells derived from tumors with heterozygous mutations or deletions of PTEN. Simvastatin was selected for use as it has been demonstrated to exert anti-proliferative and growth-inhibitory actions on a number of cancer cell lines and tumor animal models $(6,7,10,18,22,26-30)$. In accordance with these results, the present study demonstrated that simvastatin reduced the viability of PTEN mutant lipoma cells by inducing apoptosis in a time- and dose-dependent manner.

A potential mechanism of simvastatin action is the increase of PTEN protein levels and consequent suppression of AKT/mTOR signaling. This has been addressed by previous studies in various tissues, cancer cell lines and cancer xenograft animal models (8-10). In accordance with previous studies using tissues harvested from patients with PHTS $(28,34)$, the results of the present study demonstrated that PTEN protein levels are reduced and AKT activation is increased in PTEN mutant lipoma cell cultures compared with PTEN wild-type cells. Furthermore, decreased PTEN mRNA levels were only identified in lipoma cells with a large heterozygous PTEN deletion (LipPD1 cells) and not in lipoma cells with heterozygous PTEN mutations (LipPD2 and LipPD3 cells). This contrast between normal mRNA expression and low protein levels may indicate the occurrence of a post-transcriptional event, such as increased protein degradation, due to mutations in PTEN.

Simvastatin treatment resulted in a transient upregulation of PTEN mRNA and protein levels in lipoma cells. In the present study, it was investigated by which mechanism simvastatin mediated this effect. The transcriptional regulator PPAR $\gamma$ has previously been reported to upregulate the transcription of PTEN and thereby influence AKT phosphorylation in non-malignant and cancer cells $(10,19-22)$. The results of the present study demonstrate that PPAR $\gamma$ exhibits a similar expression pattern to PTEN following simvastatin stimulation of lipoma cells. However, the transient knockdown of PPAR $\gamma$ abrogated the increase in lipoma cell PTEN protein levels following simvastatin treatment. 
Additionally, PPAR $\gamma$ knockdown had no effect on simvastatin-mediated induction of apoptosis. This is in contrast to previous studies, which demonstrated that the induction of apoptosis by PPAR $\gamma$ agonists occurs via the upregulation of PTEN (10,19,22,32-34).

Previous studies have reported various pathways by which simvastatin affects cell viability that are dependent on the inhibition of the cholesterol biosynthesis pathway, including the attenuation of $\mathrm{NF}-\kappa \mathrm{B}$ activation by a decrease in intracellular isoprenoid concentrations followed by impaired inner membrane attachment and Ras, Rac or Rho protein function $(32,33)$. However, the lipoma cells used in the present study did not exhibit a decrease in NF- $\kappa \mathrm{B}$ phosphorylation following incubation with simvastatin. The action of simvastatin in prostate cancer cells may be associated with decreasing cellular cholesterol levels, leading to altered membrane lipid raft structures, causing a reduction in AKT phosphorylation and thus resulting in apoptosis (38). This effect of simvastatin on caveolar raft structures has also been demonstrated in adipocytes (39). In accordance with this, the present study detected a decrease in AKT, mTOR and the mTOR target 4EBP-1 phosphorylation following prolonged treatment with simvastatin.

In conclusion, the results of the present study support the hypothesis that simvastatin treatment reduces the growth of lipoma cells and may be a promising candidate for the treatment of lipomatosis associated with PTEN haploinsufficiency. However, the effects of simvastatin are not mediated by PPAR $\gamma$-facilitated upregulation of PTEN in lipoma cells. Further studies in suitable animal models are required to evaluate the use of simvastatin treatment in patients with lipomatosis associated with PTEN haploinsufficiency.

\section{Acknowledgements}

Not applicable.

\section{Funding}

The present study was supported by the Mitteldeutsche Kinderkrebsforschung (to FK), the European Union's Horizon 2020 research and innovation program under the Marie Sklodowska-Curie agreement (grant no. 705869; to AG) and from Deutsche Forschungsgemeinschaft/Collaborative Research Centre SFB1052/B10 (to AG and WK).

\section{Availability of data and materials}

The datasets used and/or analyzed during the current study are available from the corresponding author on reasonable request.

\section{Authors' contributions}

AG and NH conceived the study. AG, NH and FK designed the study and provided a major contribution to writing the manuscript. AG, NH, FK, TS and MP analysed data. WK interpreted patient data and discussed results. KL and AK provided expertise on adipocyte culture and knockdown experiments. FK, TS and SR performed experiments. All authors read and approved the final manuscript.

\section{Ethics approval and consent to participate}

Ethical approval for these studies was obtained from the Ethics Committee of the University of Leipzig (ref. no. 425-12-171220; Leipzig, Germany). Written informed consent was provided by the parents of all patients enrolled in the present study.

\section{Consent for publication}

Not applicable.

\section{Competing interests}

The authors declare that they have no competing interests.

\section{References}

1. Eng C: PTEN: One gene, many syndromes. Hum Mutat 22: 183-98, 2003.

2. Tan MH, Mester JL, Ngeow J, Rybicki LA, Orloff MS and Eng C: Lifetime cancer risks in individuals with germline PTEN mutations. Clin Cancer Res 18: 400-407, 2012.

3. Schmid GL, KässnerF, Uhlig HH, Körner A, Kratzsch J,Händel N, Zepp FP, Kowalzik F, Laner A, Starke S, et al: Sirolimus treatment of severe PTEN hamartoma tumor syndrome: Case report and in vitro studies. Pediatr Res 75: 527-534, 2014.

4. Hollander MC, Blumenthal GM and Dennis PA: PTEN loss in the continuum of common cancers, rare syndromes and mouse models. Nat Rev Cancer 11: 289-301, 2011.

5. Mauro VF and MacDonald JL: Simvastatin: A review of its pharmacology and clinical use. DICP 25: 257-64, 1991.

6. Desai CS, Martin SS and Blumenthal RS: Non-cardiovascular effects associated with statins. BMJ 349: g3743, 2014.

7. Zhong S, Zhang X, Chen L, Ma T, Tang J and Zhao J: Statin use and mortality in cancer patients: Systematic review and meta-analysis of observational studies. Cancer Treat Rev 41: 554-567, 2015.

8. Nielsen SF, Nordestgaard BG and Bojesen SE: Statin use and reduced cancer-related mortality. N Engl J Med 367: 1792-1802, 2012.

9. Campbell MJ, Esserman LJ, Zhou Y, Shoemaker M, Lobo M, Borman E, Baehner F, Kumar AS, Adduci K, Marx C, et al: Breast cancer growth prevention by statins. Cancer Res 66: 8707-8714, 2006 .

10. Fang Z, Tang Y, Fang J, Zhou Z, Xing Z, Guo Z, Guo X, Wang W, Jiao W, Xu Z and Liu Z: Simvastatin inhibits renal cancer cell growth and metastasis via AKT/mTOR, ERK and JAK2/STAT3 pathway. PLoS One 8: e62823, 2013.

11. Wang T, Seah S, Loh X, Chan CW, Hartman M, Goh BC and Lee SC: Simvastatin-induced breast cancer cell death and deactivation of PI3K/Akt and MAPK/ERK signalling are reversed by metabolic products of the mevalonate pathway. Oncotarget 7: 2532-2544, 2016.

12. Chen YQ, Zhao LY, Zhang WZ and Li T: Simvastatin reverses cardiomyocyte hypertrophy via the upregulation of phosphatase and tensin homolog expression. Exp Ther Med 10: 797-803, 2015.

13. Ghosh-Choudhury N, Mandal CC, Ghosh-Choudhury N and Ghosh Choudhury G: Simvastatin induces derepression of PTEN expression via NFkappaB to inhibit breast cancer cell growth. Cell Signal 22: 749-58, 2010

14. Self TH and Akins D: Dramatic reduction in lipoma associated with statin therapy. J Am Acad Dermatol 58 (2 Suppl): S30-S31, 2008.

15. Wilhelm F, Kässner F, Schmid G, Kratzsch J,Laner A, Wabitsch M, Körner A, Kiess W and Garten A: Phosphatidylinositol 3-kinase (PI3K) signalling regulates insulin-like-growth factor binding protein-2 (IGFBP-2) production in human adipocytes. Growth Horm IGF Res 25: 115-120, 2015.

16. Fischer-Posovszky P, Newell FS, Wabitsch M and Tornqvist HE: Human SGBS cells-a unique tool for studies of human fat cell biology. Obes Facts 1: 184-189, 2008.

17. Wabitsch M, Brenner RE, Melzner I, Braun M, Möller P, Heinze E, Debatin KM and Hauner H: Characterization of a human preadipocyte cell strain with high capacity for adipose differentiation. Int J Obes Relat Metab Disord 25: 8-15, 2001. 
18. Bernhard F, Landgraf K, Klöting N, Berthold A, Büttner P, Friebe D, Kiess W, Kovacs P, Blüher M and Körner A: Functional relevance of genes implicated by obesity genome-wide association study signals for human adipocyte biology. Diabetologia 56 : 311-322, 2013.

19. Tu J, Li W, Zhang Y, Wu X, Song Y, Kang L, Liu W, Wang K, Li S, Hua W and Yang C: Simvastatin inhibits IL-1 $\beta$-induced apoptosis and extracellular matrix degradation by suppressing the NF- $\kappa \mathrm{B}$ and MAPK pathways in nucleus pulposus cells. Inflammation 40: 725-734, 2017.

20. Spampanato C, De Maria S, Sarnataro M, Giordano E, Zanfardino M, Baiano S, Cartenì M and Morelli F: Simvastatin inhibits cancer cell growth by inducing apoptosis correlated to activation of Bax and downregulation of BCL-2 gene expression. Int J Oncol 40: 935-941, 2012.

21. Åberg M, Wickström M and Siegbahn A: Simvastatin induces apoptosis in human breast cancer cells in a NFאB-dependent manner and abolishes the anti-apoptotic signaling of TF/FVIIa and TF/FVIIa/FXa. Thromb Res 122: 191-202, 2008.

22. Pi WF, Guo XJ, Su LP and Xu WG: Troglitazone upregulates PTEN expression and induces the apoptosis of pulmonary artery smooth muscle cells under hypoxic conditions. Int J Mol Med 32: 1101-1109, 2013.

23. Farrow B and Evers BM: Activation of PPARgamma increases PTEN expression in pancreatic cancer cells. Biochem Biophys Res Commun 301: 50-53, 2003.

24. Vella V, Nicolosi ML, Giuliano S, Bellomo M, Belfiore A and Malaguarnera R: PPAR- $\gamma$ agonists as antineoplastic agents in cancers with dysregulated IGF axis. Front Endocrinol (Lausanne) 8: 31, 2017.

25. Wang G, Cao R, Wang Y, Qian G, Dan HC, Jiang W, Ju L, Wu M, $X i a o$ Y and Wang X: Simvastatin induces cell cycle arrest and inhibits proliferation of bladder cancer cells via PPAR $\gamma$ signalling pathway. Sci Rep 6: 35783, 2016.

26. Marsh DJ, Trahair TN, Martin JL, Chee WY, Walker J, Kirk EP, Baxter RC and Marshall GM: Rapamycin treatment for a child with germline PTEN mutation. Nat Clin Pract Oncol 5: 357-361, 2008.

27. Iacobas I, Burrows PE, Adams DM, Sutton VR, Hollier LH and Chintagumpala MM: Oral rapamycin in the treatment of patients with hamartoma syndromes and PTEN mutation. Pediatr Blood Cancer 57: 321-323, 2011

28. Heindl M,HändelN,Ngeow J,Kionke J, Wittekind C,KampradM, Rensing-Ehl A, Ehl S, Reifenberger J, Loddenkemper C, et al: Autoimmunity, intestinal lymphoid hyperplasia, and defects in mucosal B-cell homeostasis in patients with PTEN hamartoma tumor syndrome. Gastroenterology 142: 1093-1096.e6, 2012.
29. Relja B, Meder F, Wilhelm K, Henrich D, Marzi I and Lehnert M: Simvastatin inhibits cell growth and induces apoptosis and G0/G1 cell cycle arrest in hepatic cancer cells. Int J Mol Med 26: 735-741, 2010.

30. Liang Z, Li W, Liu J, Li J, He F, Jiang Y, Yang L, Li P, Wang B, Wang Y, et al: Simvastatin suppresses the DNA replication licensing factor MCM7 and inhibits the growth of tamoxifen-resistant breast cancer cells. Sci Rep 7: 41776, 2017.

31. Wang ST,Ho HJ,Lin JT, Shieh JJ and Wu CY: Simvastatin-induced cell cycle arrest through inhibition of STAT3/SKP2 axis and activation of AMPK to promote p27 and p21 accumulation in hepatocellular carcinoma cells. Cell Death Dis 8: e2626, 2017.

32. Cafforio P, Dammacco F, Gernone A and Silvestris F: Statins activate the mitochondrial pathway of apoptosis in human lymphoblasts and myeloma cells. Carcinogenesis 26: 883-891, 2005.

33. Denoyelle C, Vasse M, Körner M, Mishal Z, Ganné F, Vannier JP, Soria $\mathbf{J}$ and Soria C: Cerivastatin, an inhibitor of HMG-CoA reductase, inhibits the signaling pathways involved in the invasiveness and metastatic properties of highly invasive breast cancer cell lines: An in vitro study. Carcinogenesis 22: 1139-1148, 2001.

34. Chen HH, Händel N, Ngeow J, Muller J, Hühn M, Yang HT, Heindl M, Berbers RM, Hegazy AN, Kionke J, et al: Immune dysregulation in patients with PTEN hamartoma tumor syndrome: Analysis of FOXP3 regulatory T cells. J Allergy Clin Immunol 139: 607-620.e15, 2017.

35. Lin CF, Young KC, Bai CH, Yu BC, Ma CT, Chien YC, Chiang CL, Liao CS, Lai HW and Tsao CW: Rosiglitazone regulates anti-inflammation and growth inhibition via PTEN. Biomed Res Int 2014: 787924, 2014

36. Aiello A, Pandini G, Frasca F, Conte E, Murabito A, Sacco A, Genua M, Vigneri R and Belfiore A: Peroxisomal proliferator-activated receptor-gamma agonists induce partial reversion of epithelial-mesenchymal transition in anaplastic thyroid cancer cells. Endocrinology 147: 4463-4475, 2006.

37. Han S and Roman J: Rosiglitazone suppresses human lung carcinoma cell growth through PPARgamma-dependent and PPARgamma-independent signal pathways. Mol Cancer Ther 5: 430-437, 2006.

38. Zhuang L, Kim J, Adam RM, Solomon KR and Freeman MR: Cholesterol targeting alters lipid raft composition and cell survival in prostate cancer cells and xenografts. J Clin Invest 115: 959-968, 2005.

39. Khan T, Hamilton MP, Mundy DI, Chua SC and Scherer PE: Impact of simvastatin on adipose tissue: Pleiotropic effects in vivo. Endocrinology 150: 5262-5272, 2009. 